Author: Emma Marya COONAN (M.St., M.Sc., Ph.D.), Research Skills \& Development Librarian, Cambridge University Library

Mailing address: Reader Services, Cambridge University Library, West Road, Cambridge CB3 9DR, UK

Email address: emma.coonan@lib.cam.ac.uk

Keywords: information literacy; information retrieval; information-seeking behaviour; taxonomy; research skills

Short title: Navigating the information landscape

Abstract: This article explores the tension between the structures by which the library organises and presents information, and the ways in which students and researchers access, use and conceptualise knowledge. I suggest that while knowledge structures are vital to learning and research, an overemphasis on structurality is mistaken, and can lead to an inappropriately positivist approach which impedes the research mission. The article examines various metaphoric ways of negotiating meaning and navigating information structures, and of crossing the threshold of structurality.

This work has not been published elsewhere and has not been submitted simultaneously for publication elsewhere. 


\section{Navigating the information landscape}

\section{Visions of order}

In the library world we have arrived at a point where the combination of technological advances and taxonomy seems to bring within reach the visions of total order which underlie the libraries of Eco and Borges, those complex arrangements of knowledge in which "the plan of the library reproduces the map of the world"1 and which to scholars or to librarians may indeed comprise the world:

The universe (which others call the Library) is composed of an indefinite and perhaps infinite number of hexagonal galleries, with vast air shafts between, surrounded by very low railings. From any of the hexagons one can see, interminably, the upper and lower floors .... I say that the Library is unending. ${ }^{2}$

Faced with this alarming, here-be-dragons infinitude humans turn to order and system to bring meaning to our phenomenological world. Order lets us map the terrain, chart the boundaries, recognise likenesses and landmarks. It asserts deeply reassuring concepts of identity, relationship and familiarity within reach. From the garden of Eden to the periodic table of elements, the vision of an ordered universe has led us to classify and arrange elements into systematic and hierarchical structures of identity and association, such as Dewey with its "well-defined categories, welldeveloped hierarchies, and a rich network of relationships among topics".3

As Clay Shirky writes ${ }^{4}$, ontology has to do with defining the essence or "Is-ness" of things within a particular domain, and showing where they stand in relation to one another. Within the systems Shirky examines, such as the periodic table and some forms of library classification, the structure itself creates predetermined places for all entities in the domain. Structural order defines both unique and relational identity: it tells you what things are by where they stand, and by these means, it offers a deep existential comfort - how reassuring to know that Dewey is "divided into ten main 


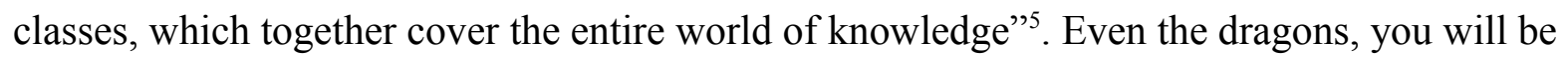
pleased to know, may be classed at 398.469 .

Through ontologies, taxonomies or other hierarchical structures, therefore, we achieve a meaningful grasp of the phenomenological world which would otherwise overwhelm us. T. S. Eliot wrote in 1923 of "the immense panorama of futility and anarchy which is contemporary history" rendered meaningful by Joyce's use of mythological order in Ulysses. Frank Kermode likewise analyses the patterns of thought which bring coherence and significance to our lives by projecting beginnings and ends beyond the human life-span: humans, he argues

rush 'into the middest', in medias res, when they are born; they also die in mediis rebus, and to make sense of their span they need fictive concords with origins and ends, such as give meaning to lives and to poems. ${ }^{7}$

Structurality is not, however, only a fictive strategy, nor confined to the discourse of literary theory. It is a function of human nature, Kermode claims, to "make considerable imaginative investments in coherent patterns" ${ }^{\prime \prime}$. An example of this investment appears in the recent research project $A$ New Curriculum for Information Literacy, in which an expert in the information field describes an educational culture which circumscribes knowledge into manageable boxes:

we draw these boxes to simplify the immense complexity we face, but I think that increasingly we are, in the information society, having to interact directly with this complexity and additional strategies for dealing with it (beyond that of imposing order on it) are needed. ${ }^{9}$

We cannot live without some form of structure to give us meaning, value and direction in our lives. In many cases our desire for pattern and identity becomes a search for an anterior or ultimate pattern, a total order which both prefigures and encloses infinity: 
The Library is unlimited and cyclical. If an eternal traveller were to cross it in any direction, after centuries he would see that the same volumes were repeated in the same disorder (which, thus repeated, would be an order: the Order). My solitude is gladdened by this elegant hope. ${ }^{10}$ Thus structure allows us to parcel up and pattern an otherwise overwhelming, inchoate or undifferentiated reality; but it can also lead to a focus on structurality for its own sake. Ontologies and taxonomies are plausible things, lovely in their symmetry as well as genuinely helpful in managing large volumes of information; and it is not surprising if these structures of knowledge about the world, tortuous yet dependable pathways into understanding, are occasionally mistaken for the world itself.

Hence the class and reference desk time we devote to giving our readers an understanding of library systems of organising, classifying, arranging and retrieving information, and the ardour with which we greet the 'teachable moment' when we can explain how to use them properly: this is what subject headings are all about! You see, the surname comes first, and the first name second! Ah, you've been searching for the article title, but what you need to look for is the journal title!

Given the extent and frequency of our attempts to explain (and sometimes to defend) our systems, it is unsurprising that commentators such as Wilder argue that our mission seems to be to propagate complexity:

It is not uncommon for librarians to speak, for example, of the complexity of searching for journal articles as if that were a fact of life. ... Almost any student could suggest a better alternative: that the library create systems that eliminate the need for instruction. ${ }^{11}$

In a recent blog post Greyson recounts a library system encounter that ended sorrowfully - a not uncommon tale of a missing book and a less-than-helpful 'report a problem' button in the OPAC. As 
the author writes, such experiences make advocating for the university library hard: "Some days I'm afraid to tell [faculty colleagues] too much about the library, in case they actually try to use it and have an experience like the one above"12. Yet a subsequent post by another library blogger notes astutely that while this is self-evidently an important issue, "what do some of the comments say? They say 'Greyson, you're doing it wrong'."

Not only were people annoyed that someone who did something in an unexpected way dared to complain, a few of the commenters seemed personally offended at an apparent attack on their work. This misses the point. There's no point trying to defend a broken system by pointing out how hard you and/or your colleagues are working, or how much you yearn to help people with their queries. ${ }^{13}$

The 'you're doing it wrong' response can, of course, be a product rather than a cause of the library's devotion to order, born of a genuine desire to help readers better comprehend advanced and complex systems. However, the effect is to position the library staff member as an expert on information and the researcher as an inexpert user in need of guidance - in Seth Godin's words "the interface between reams of data and the untrained but motivated user" ${ }^{\prime 14}$ - whereas in fact it is far more frequently the case that library staff are experts on information organisation.

We know the good places to look, and we know the pitfalls of too casually-constructed a search strategy (and we also know the cost of subscribing to quality academic databases, so we'd like our students to get use out of them). We are understandably eager to communicate all this knowledge, to enlighten our students about how an understanding of how information is organised can help them become better researchers. The 'doing it wrong' approach thus spills over into our library instruction and information literacy sessions too. Although the purpose of information skills classes is to develop students' research capabilities, it is rare that we move away from presentations, 
demonstrations, and instruction about library resources. It is as though we have roped off a designated space of selected information in order to create not merely an ordered but a bounded space, a safe haven of sources chosen for their authority, veracity or integrity, with a kindly and knowledgeable guide to point the way with certainty.

The New Curriculum for Information Literacy research project explores the image of the academic library's resources as a cloistered garden of scholarship sheltered within the defining walls ${ }^{15}$. Barbara Fister employs the same metaphor of ordered enclosure to describe the subscription barriers which create "walled gardens of overpriced material only available to the few"16. Within these walls the librarian's role is reminiscent of I. A. Richards's metaphoric vision of Definition as outlined in The Meaning of Meaning: "A person thoroughly acquainted with his subject and with the technique of Definition should be able, like the man up aloft in a maze, to direct travellers from all quarters to any desired point ..."17. Once again, however, it is worth remembering that our subject is not information, but the structures through which we mediate and organise it. When we point the way through the maze we are directing researchers through an artificial system of our own designing. As Wilder argues, a student using the library's website

with its dozens of user interfaces, search protocols, and limitations ... might with some justification conclude that is the library, not her, that needs help understanding the nature of electronic information retrieval ${ }^{18}$.

Structurality can lure us into the belief that in order to be either accessible or useful, information must be bounded and explicitly subjected to systematic and hierarchical order. If we fall into the trap of confusing information with information organisation, anything not described in taxonomic classes seems to us to be outside the structure of knowledge: uncategorised and therefore untrustworthy, in freefall in "an unbounded and diverse information environment"19. 
The temptation of course is to polarise the library and the web - or, in many cases, the ubiquity of Google - as, respectively, an orderly and secure bounded space and a chaotic and uncharted terrain beyond the frontier. In an era of democratized search and disintermediation, with librarians valiantly arguing that 'not everything is on the web', it sometimes feels as though our profession's survival rests on two points only: the subscription content concealed behind our cloistered walls, and the refined sophistication of our systems for describing it. The existence of the web seems to threaten not merely existing structures, but the need for descriptive structurality itself: "If you've got a large, ill-defined corpus, if you've got naive users, if your cataloguers aren't expert, if there's no one to say authoritatively what's going on" (which Shirky argues is "an almost perfect description of the Web"), then "ontology is going to be a bad strategy"20.

Library vs. Web is a persuasive opposition and the subject of many a well-argued and compelling polemic - Phil Bradley's "What librarians \& Google are for" ${ }^{21}$ is one such - but it's worth remembering that Google's mission too is predicated on order and access, aiming as it does "to organize the world's information and make it universally accessible and useful" ${ }^{\text {22 }}$. As Shirky points out, the real-time sorting of information performed by search engine users doesn't demonstrate a lack or refutation of organisation, merely a different mechanism for effecting it: a just-in-time, usercreated, customised organisation rather than a predetermined taxonomy.

However, the opposition persists. Information use and behaviour in the online environment, we are told, is very different from traditional ways of navigating physical surroundings. With the move from information scarcity to information abundance the emphasis shifts from expert guidance to user empowerment: 
library users have rapidly become information consumers who can switch instantly between commercial search engines, social networking sites, wikis, bookmarked resources and electronic services provided by their library to satisfy their information needs. ${ }^{23}$

In response to this multiplicity of sources the CIBER 2008 report famously described how "a whole new form of online reading behaviour is beginning to emerge, one based on skimming ..."24 - and gave rise to a profession-wide anxiety about our students' and researchers' ability to discriminate. Out there beyond the library (pay)walls, beyond our guidance, wandering in the "uncharted territory" ${ }^{25}$ of the web - limitless, decentred, unfixed and chaotic - would they be able to assess critically the validity as well as the value of information?

Navigating in an open information domain, they are unable to rely on expert guidance, organisation or classification. Their choices at different points of navigation may lead them into new informational territory which they did not previously know was there, or which they had not previously realised may be relevant. Their purpose may therefore shift during their search $\ldots^{26}$

The casual nature of the "bouncing/flicking" and "power browsing",27 behaviours identified by CIBER has led to a fear that students and researchers in the digital age are failing to engage deeply and actively with intellectual content. An academic quoted in the 2009 JISC report on ebooks argues that 
using the search facility in a textbook is equivalent to using that textbook as a reference work / encyclopaedia, which is inappropriate use as textbooks are not written as

encyclopedia[s]; they are written to be read rather than mined for facts. ${ }^{\mathbf{2 8}}$

Yet such 'mining for facts' - in however inappropriate a source - is not new information behaviour by any means. Printed academic books are supplied with indexes so that readers may skip to specific sections in much the same way as hitting Control-F, albeit with a more limited and a preselected range of keywords: "even in the print environment, books were more often used as databases than as texts for extended linear reading (regardless of what their authors may have intended) ${ }^{, 29}$. Likewise, skimming and scanning are techniques very frequently both practised and taught for use with printed matter: how else to wade through the titles on your reading list? These non-linear behaviours may be performed more online; but that doesn't license us to create a polarised opposition between print and electronic information consumption.

Most importantly, however, we should not allow ourselves to imagine that the accidental discovery of 'new informational territory' and corresponding shifts in focus are products of the digital era. Scholarly serendipity is nothing new: experienced researchers know that it's not the book you went to the shelf to get that's the one you really want, but the one next to it ... And indeed it is in the juxtaposition of previously unrelated viewpoints, in the synthesis of variant or conflicting theories, that insights are achieved. Research is not about navigating the known, but about stumbling across the gaps, experiencing the shifts in focus that take the researcher by surprise. 
Thus to assert that such behaviours are new, different, and caused by the online environment is not only to reassert the simplistic and unhelpful oppositions of library and web, structure and chaos, but also to misunderstand the very nature of research itself.

\section{The secret life of the researcher}

As I have argued elsewhere ${ }^{30}$, achieving insight or innovative thought has less to do with finding answers than with framing problems or asking questions that disconcert existing assertions, definitions, or knowledge structures: "Creative intelligence is the ability to formulate good problems" ${ }^{\prime 31}$. Research thus requires not only a firm and sophisticated grasp of existing structures of thought, but the courage and intellectual curiosity to bring into question their assertions and relationships, to poke into their very structurality itself. Like Kipling's mongoose, researchers are "eaten up from nose to tail with curiosity"; their motto too should be "Run and find out" 32 .

Just as we feel we know how people read, both on- and offline, so we also feel we know how researchers should go about this process of finding out. The idea of a 'right way' and a 'right place' in which to search still haunts librarianship - don't use Google, use a subscription database! don't use Wikipedia, you can't rely on it! (As though researchers should permit themselves ever to rely uncritically on any resource, however academically august.)

Our belief in a 'right way' and 'right place' is generally based on a deeply-held adherence to the principles of veracity, authenticity, and currency. This is both admirable and useful, and should form a crucial part of the critical and evaluative armoury of researchers. Yet rather than designing our information literacy sessions to offer students the chance to develop this critical sensibility independently, we too frequently substitute a paternalistic form of guidance. Our desire to signpost the correct way can lead us to stipulate certain sources, tools, criteria and actions that are 'safe', 
'appropriate', or simply right for researchers. As Andrew Whitworth comments, "this type of information literacy teaching fails even on its own terms.... it cannot be effective at embedding in students a flexible, enquiring attitude" ${ }^{33}$. In our zeal to point the right way we can end up working against criticality and undermining the potential development of our students as discerning, autonomous scholars capable of designing strategies for assessing, judging and assimilating information from any source, whether within the walls of the library's cloistered garden or out in the wilder territory of the web - or in information environments yet to emerge, for which we have no guidance to offer and no designated boundaries within which to operate.

As part of our focus on 'doing it right' we teach students that gathering information is a separate activity, with different procedures, from evaluation, which is separate again from writing and presenting. Models and standards of information literacy attempt to describe the complex processes involved in research, and end by forcibly separating them into linear and successive components: they "implicitly separate searching from doing something with what you've found" 34 . Searching, like researching, is always a work in progress, a construction or negotiation of meaning. Patterns form, connections are made; trends in the research topic emerge; the search evolves, becoming "a creative and critical part of the research process" ${ }^{\prime 35}$. Yet by endeavouring to break down the research process into definable component parts, library models inadvertently disconnect and render static an active, evolving process - an interaction between the researcher and the found content which leads to the spark of innovative thought. As Fister describes it, (re)search is about "the thrill of the chase" ${ }^{, 36}$; yet in our anxiety to show the way, to direct and define, librarians have reappropriated research and "fix[ed] an assertorial clip" 37 on it, directing the pursuit into safer, known pathways in a laudable but misplaced desire to save students from losing their way. 
Let us then retrace our steps to the analogy of information as a labyrinth. In Marshall \& Green's Your PhD Companion the process of doctoral research is described thus:

When you start off, you may only have a vague idea which direction to set out in, or even how big the maze is .... all sorts of possibilities open up, you turn this way and that. The walls close in on you either side. After a while you may feel lost. You get the feeling you have been going round in circles. You wonder if you will ever find a way out. ${ }^{38}$

This analogy captures vividly the non-linearity of the research journey, with its doublings back, false trails and frustrations. Lovitts notes that knowledge "often results from uncertain processes that take place in unstructured contexts" rather than in "tightly bounded and controlled environments" ${ }^{\prime 39}$ such as the classroom or lecture hall - or the library system. To go in search of the new, to make a contribution to knowledge, means going beyond the comfort of the known, crossing a threshold, to balance on the edge of structurality. The uncertain wandering creates doubt and hesitation: "spending a certain amount of time in a liminal state may be a defining characteristic of the doctoral process" 40 . Troublesome knowledge is matched by "troublesome process within learning development" ${ }^{41}$; but eventually the researcher negotiates a way out of the maze, or across the threshold, and into new territory: not under the magisterial guidance of a Definitional figure, but in a dynamic negotiation of meaning between the researcher and the information context.

Where we've gone wrong, then, is to try to give people the answers. If the fundamental nature of research is to pose questions that problematise knowledge, we can forget about a golden age of library usage when all researchers needed to know was "how to find precisely the right information, in a finite repository, by skillful searching" 42 and gratefully relied upon "expert guidance, organisation or classification"43, since the concept of 'the right information' is precisely the kind of positivist assertion being brought into question. In order to stumble across new knowledge, 
researchers need to lose their way inside knowledge structures: only by this means can they find a way out to insight and innovation.

The research process is thus an emergence from the structures of what is already known, a goingbeyond or going-outside. Our desire to identify and define knowledge to the point of absolute stability is at odds with the concept of research as a quest for innovation. To insist on the monolithic inclusivity or permanence of our structures of knowledge is to assert, once again, 'You're doing it wrong'.

Yet the greatest threat to our structures of knowledge lies precisely and paradoxically in their apparent solidity and stability. At the moment when they appear to have gained a sophistication and complexity that means they not only mirror the world but explain - or contain - it, at the point where we can insist 'You're doing it wrong', they become vulnerable, because a monolithic vision is utterly dependent on being right. Not merely partly right or usually right, but absolutely and completely right in every aspect of its representation of the world. The smallest shift towards uncertainty, the slippage of the tiniest taxonomic element, can open a crack in knowledge capable of consuming the entire structure. One stealthy tweak, and whoosh: the towering edifice crumples and shatters. Take the platypus:

... profound puzzlement was felt in 1797 by the first Europeans to observe the duck-billed platypus, which couldn't be accommodated anywhere in the existing zoological classifications. It was considered variously to be related to the mole, the beaver and the turtle, and to be a bird, amphibian, reptile or mammal .... eventually the taxonomies had to be reconstructed to accommodate it. ${ }^{44}$

Knowledge lurks in unexpected places: in the flashes of insight that create new hypotheses and questions; in the juxtaposition and synthesis of divergent points of view; in the cracks and 
interstices of the taxonomies. Without structure, knowledge cannot emerge in this gleeful, inquisitive, innovative way; but structurality is not 'the answer', nor a faithful mirror of the universe. An awareness that there are different forms of structuration, different ways of dividing up the vast inchoate body of information, all of which are equally valid, may be a threshold concept in itself, and may liberate us to recognise that our structures and systems are merely a kind of convenient shorthand; familiar, established, even loved sets of boxes into which to place information concepts. Ultimately, they are the source not of consolatory answers but of endless questions: and in the words of one of the greatest challengers of established order, the important thing is not to stop questioning. 
1 Umberto Eco, The Name of the Rose (London: Picador, 1984), 314.

2 Jorge Luis Borges, “The Library of Babel,” Labyrinths (Penguin, Harmondsworth, 1970), 78.

$3 \mathrm{http} / /$ www.oclc.org/dewey/resources/summaries/

4 Clay Shirky, “Ontology is Overrated," Clay Shirky's Writings About the Internet, 2005, http://www.shirky.com/writings/ontology_overrated.html.

5 http://www.oclc.org/dewey/resources/summaries/

6 T. S. Eliot, “Ulysses, Order, and Myth,” Dial 75, no.5 (1923): 483.

7 Frank Kermode, The Sense of an Ending: Studies in the Theory of Fiction (Oxford: Oxford University Press, 2000$), 7$.

8 Ibid, 17.

9 Jane Secker, A New Curriculum for Information Literacy. Expert Consultation Report, July 2011, 6. http://ccfil.pbworks.com.

10 Borges, “Library of Babel”, 85-6.

11 Stanley Wilder, “Beyond information literacy,” Rochester Review 68, no. 1 (2005), http://www.rochester.edu/pr/Review/V68N1/inrev15.html.

12 Greyson, "How academic libraries annoy academics," Social Justice Librarian [blog], July 2011, http://sjlibrarian.wordpress.com/2011/07/26/how-academic-libraries-annoy-academics/.

13 Katie Birkwood, "Doing it wrong," Girl in the Moon [blog], July 2011, http://maedchenimmond.blogspot.com/2011/07/doing-it-wrong.html.

14 Seth Godin, “The future of libraries,” Seth Godin's Blog, May 2011, http://sethgodin.typepad.com/seths_blog/2011/05/the-future-of-the-library.html.

15 Emma Coonan, A New Curriculum for Information Literacy. Teaching Learning: Perceptions of Information Literacy, July 2011, 12. http://ccfil.pbworks.com.

16 Barbara Fister, “Search: How Libraries Do it Wrong,” Inside Higher Ed [blog], August 2011, http://www.insidehighered.com/blogs/library_babel_fish/search_how_libraries_do_it_wrong.

17 C.K. Ogden \& I.A. Richards, The Meaning of Meaning (London: Kegan Paul, Trench, Trubner, 1923$), 116$

18 Wilder, "Beyond information literacy".

19 Ian Beeson, “Judging relevance: a problem for e-literacy,” Italics 5, no.4 (2006): 210.

http://www.ics.heacademy.ac.uk/italics/vol5iss4.htm.

20 Shirky, “Ontology”.

21 Phil Bradley, “What Librarians \& Google Are For ...," Phil Bradley's Weblog, June 2011. http://philbradley.typepad.com/phil_bradleys_weblog/2011/06/what-librarians-google-are-for.html.

22 http://www.google.com/about/corporate/company/

23 CIBER, Information behaviour of the researcher of the future, 2008, 8. http://www.ucl.ac.uk/infostudies/research/ciber/downloads/.

24 Ibid, 31. 
25 Beeson, “Judging Relevance”, 214.

26 Ibid, 215.

27 CIBER, Researcher of the Future, 31.

28 CIBER, JISC National Ebooks Observatory Project: Headline findings from the user surveys, 2009, http://www.jiscebooksproject.org/wp-content/JC-CIBER_UserSurveyFindings_Report_v1-01.pdf

29 Rick Anderson, “The Crisis in Research Librarianship,” Journal of Academic Librarianship, 37, no.4 (2011): 290

30 Coonan, Teaching Learning.

31 Barbara E. Lovitts, "Being a Good Course-taker is Not Enough: a Theoretical Perspective on the Transition to Independent Research,” Studies in Higher Education 30, no. 2 (2005): 143.

32 Rudyard Kipling, "Rikki-Tikki-Tavi,” http://www.cs.cmu.edu/ mongoose/rtt.html.

33 Andrew Whitworth, "Communicative competence in the information age: towards a critical theory of information literacy education,” Italics 5, no. 1 (2006):8. http://www.ics.heacademy.ac.uk/italics/vol5iss1.htm.

34 Fister, "Search".

35 Ibid.

36 Ibid.

37 I. A. Richards, Speculative Instruments (London: Routledge \& Paul, 1955), 148.

38 Stephen Marshall \& Nick Green, Your PhD Companion (Oxford: HowTo Books, 2004), 63.

39 Lovitts, “Being a Good Course-taker”, 138.

40 Carol Edwards, "Investigation of the relevance of the notion of a threshold concept within generic learning development work," Journal of Learning Development in Higher Education 3 (2011): 9.

http://www.aldinhe.ac.uk/ojs/index.php?journal=jldhe

41 Ibid, 10.

42 Beeson, “Judging Relevance”, 210.

43 Ibid, 215.

44 Vanda Broughton, Essential Classification (London: Facet, 2004): 15-16, emphasis mine. 